\title{
Assessment of the Horizontal and Vertical Position of Mental Foramen in Indian Population in Terms of Age and Sex in Dentate Subjects by Pano- ramic Radiographs: A Retrospective Study with Review of Literature
}

\author{
Priyanka Parnami ${ }^{1}$, Deepak Gupta ${ }^{2, *}$, Vishal Arora ${ }^{3}$, Saurabh Bhalla ${ }^{4}$, Adarsh Kumar $^{5}$ and \\ Rashi Malik ${ }^{6}$
}

${ }^{I}$ Department of Oral Medicine and Radiology, Pacific Dental College and Hospital, Udaipur, India; ${ }^{2}$ Department of Oral Medicine and Radiology, M.M. College of Dental Sciences and Research, Mullana, Ambala, Haryana, India; ${ }^{3}$ Department of Orthodontics, SKSS Dental College, Ludhiana, India; ${ }^{4}$ U.P.R.I.M.S. Saifai Medical College, Uttar Pradesh, India; ${ }^{5}$ Department of Endodontics, Purvanchal Institute of Dental Sciences, Gorakhpur, India; ${ }^{6}$ Department of Pedodontics, Sardar Patel Post graduate Institute of Dental and Medical Sciences, Lucknow, UP, India

\begin{abstract}
Objective: To familiarize new criteria to access vertical position of mental foramen in panoramic radiographs. Furthermore, to determine and compare the position and symmetry of mental foramen in horizontal as well as in vertical plane in Indian population and to compare the results with those reported for other populations in the literature. Further gender differences in mental foramen position were also accessed to comment on the reliability of panoramic radiographs for sex determination. Methods and Material: Six hundred digital panoramic radiographs were selected and studied regarding the location and symmetry of mental foramen. They were also compared with the other studies in the literature. The method employed is similar to that described by Al Jasser and Nwoku for horizontal position and Fishal et al. for vertical position of mental foramen. Certain modifications were carried out in Fishal's criteria for vertical position assessment. Results: The commonest position of the mental foramen in horizontal plane was in line with the longitudinal axis of the second premolar $(61.0 \%)$ while in vertical plane it was found to be located inferior to the apex of second premolar (72.2\%). Conclusion: Mental foramen exists in different locations and possesses many variations. Hence, Individual, gender, age, race and assessing technique largely influence these variations. It suggests that the clinicians should carefully identify these anatomical landmarks, by analyzing all influencing factors, prior to their diagnostic or the other dental, surgical and implant operation.
\end{abstract}

Keywords: Horizontal position, mental foramen, panoramic radiographs, vertical position.

\section{INTRODUCTION}

The mental foramen is a funnel-like opening located on the anterolateral aspect of the mandible which marks the termination of the mandibular canal. The mental foramina (MF) are structures that are commonly encountered in various maxillofacial, craniofacial and facial plastic surgery procedures. The nerves and vessels that they transmit provide sensory innervations and blood supply to important facial structures including the soft tissues of the chin, lower lip and gingiva on the ipsilateral side of the mandible [1]. As these nerves are susceptible to injury during the placement of local anaesthesia and surgery, it is important to have a method of quickly and accurately predicting the location of the foramina they traverse.

Variation in the position and of mental foramen is common and hence can cause complications during surgical procedures $[2,3]$. The knowledge of its position also aids in the administration of local anaesthesia for surgical, endodontic as well as diagnostic procedures [2,3]. Furthermore, the mental foramen is a strategically important landmark during

\footnotetext{
*Address correspondence to this author at the Department of Oral Medicine and Radiology, M.M. College of Dental Sciences and Research, Mullana, Ambala, Haryana, India; Pin: 133203; Tel: +91-9896671281; Fax: +911731-304111; +91-1731-304550; E-mail: drdeepak_26@rediffmail.com
}

osteotomy procedures. Its location and the possibility that an anterior loop of the mental nerve may be present mesial to the mental foramen needs to be considered before implant surgery to avoid mental nerve injury [4]. The mental nerve injury can cause transitory or permanent sensitive, thermal and tactile changes [5]. In addition, in case of edentulous patients, as the atrophy progresses, the mental foramen becomes situated at the top of the alveolar crest and may cause difficulty in denture wearing [2]. A number of studies have shown difference in the position of the mental foramen according to the ethnic group studied. The literature shows studies conducted on Asians, Africans, and Caucasians [5].

The development of implant techniques further increased the interest in the mandibular anatomy, specially the mental foramen localization. Despite this interest, a small number of papers have been published on the position of mental foramen in both horizontal as well as in vertical position. In addition, the Indian population constitutes different ethnic subpopulations due to which they show high degree of miscegenation and the literature on the location of the mental foramen in this population is very scarce.

The identification and moreover the actual location of the mental foramen aid in surgical, operative, diagnostic, prosthetic as well as in endodontic procedures. The usual position of mental foramen is studied by various authors limited 
to horizontal plane. Furthermore, the position of mental foramen is never compared in both horizontal as well as vertical plane in Indian population. Henceforth, the aim of this paper is to familiarize new criteria for vertical position of mental foramen and to evaluate the position of the mental foramen in horizontal as well as in vertical planes in dentate subjects of Indian population attempting to spot a light to surgical interventions and anaesthetic block procedures. The gender differences were also accessed to comment on the reliability of panoramic radiographs for sex determination in terms of mental foramen position. Furthermore, the results were compared with those reported for other populations in the literature.

\section{MATERIAL AND METHODS}

The method employed is similar to that described by Al Jasser and Nwoku [2] for horizontal position and Fishal et al. [6] for vertical position of mental foramen. Certain modifications were carried out in Fishal's criteria for vertical position assessment. Panoramic radiographs of Indian population from 2010 to 2013 were obtained from Oral Medicine and Radiology department of our college comprising of patients of different regions of Indian population. Patients with mixed dentition were eliminated because of the possibility that a permanent tooth bud might obscure the mental foramen. All the panoramic radiographs were shot by digital panoramic machine (Orthophos XG 5 DS Ceph) by Sirona. All these radiographs were divided into two groups named as Group A and Group B.

Selected radiographs comprised of 600 completely dentate patients within the age range of 15-59 years with equal number of males and females. The mean age for males and females was 28.2 years and 27.4 years, respectively.

Radiographs were chosen according to following criteria:

a) High quality with respect to angulation, contrast and least artefacts in the mental foramen region.

b) All mandibular teeth present from left first molar to right first molar so as to eliminate any chances of mesial shift of the teeth.

c) The films must be free from any radiolucent or radiopaque lesions in the lower arch and showed no exposure or processing artefacts.

d) Radiographs in which the lower teeth (between canine to first molars) had deep caries, root canal treatment or various restorations were eliminated because of possible associated periapical radiolucency.

e) No history of previous orthodontic treatment done.

f) Radiographs in which upper premolars were missing were eliminated because of the possibility of over eruption of lower premolars which can hinder the position of mental foramen in vertical plane.

g) All panoramic radiographs where mental foramen could not be identified were excluded from the study. In agreement with Yosue and Brooks [7], these were considered to be those cases classified as 'unidentified type' of mental foramen $[7,8]$.
Radiographs were read by three observers including the principle investigator. Both of the two observers were calibrated by the principle investigator and their readings were repeated with a random sample of 30 radiographs which were re-examined by the principle investigator. Differences in the observations were resolved with forced consensus.

The Position of the Image of the Mental Foramen in Horizontal Plane was Recorded as Follows [2] (Fig. 1):

Position 1: Situated anterior to the first premolar.

Position 2: In line with the first premolar.

Position 3: Between the first and second premolar.

Position 4: In line with second premolar.

Position 5: Between the second premolar and first molar.

Position 6: In line with the first molar.

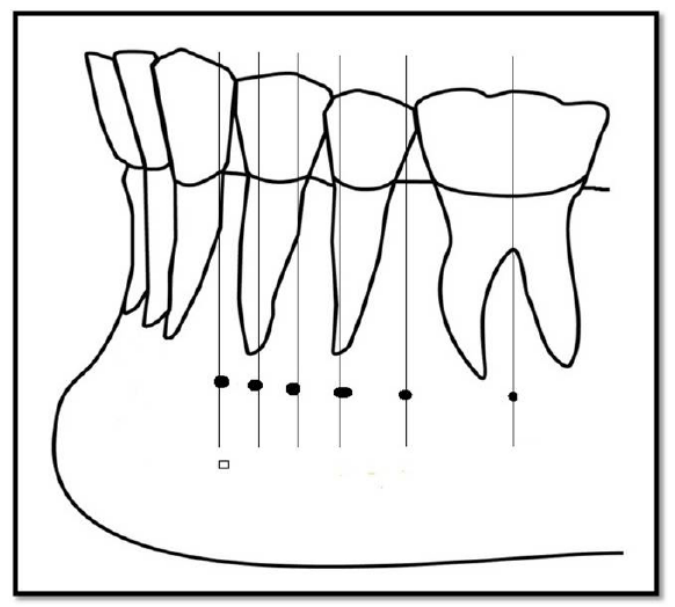

Fig. (1). Horizontal assessment of mental foramina

The Position of the Image of the Mental Foramen in Vertical Plane was Recorded as Follows (Fig. 2) According to New Criteria by Deepak Gupta:

a) Superior to the apex of first premolar

b) At or in line with the apex of first premolar

c) In between the apex of first and second premolar.

d) At or in line with the apex of second premolar

e) Inferior to the apex of second premolar

The above criteria (developed by Deepak Gupta) were considered in contrast to the criteria of Fishel et al. [6] to access vertical position of mental foramina as these criteria illustrate the vertical position of mental foramen more precisely and more accurately. According to Fischel criteria, each and every radiograph was accessed separately for vertical position of mental foramen in relation to first and then for second premolar. Hence, calculations were done twice. Furthermore, it does not give the exact vertical position of mental foramen. The reason being, the root of first premolar is shorter as compared to the root of second premolar [6]. Hence in radiographs, according to Fishel, if the vertical position of mental foramen is recorded as inferior to first premolar, it may or may not be inferior to second premolar. 
Hence the above modified criteria were considered to access the vertical position of mental foramen in panoramic radiographs.

According to Yosue and Brooks, when there appeared to be multiple foramina, the true radiographic mental foramen was considered to be the uppermost one [8].

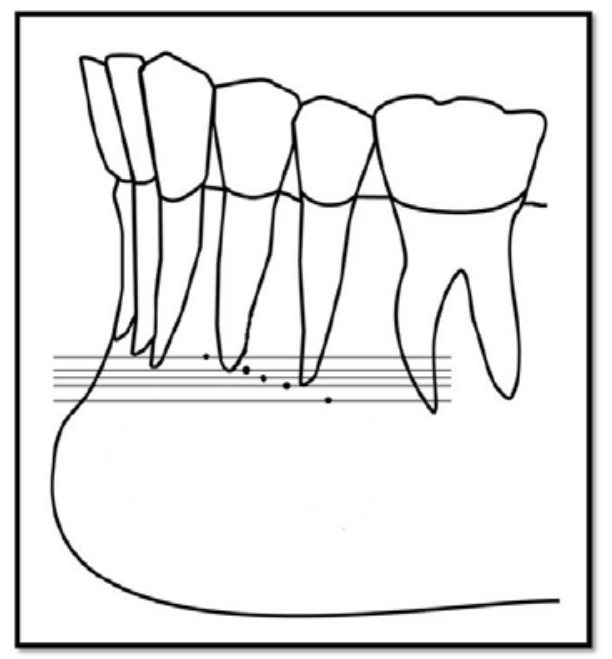

Fig. (2). New criteria of vertical assessment of mental foramina.

\section{RESULTS}

Of the 600 panoramic radiographs analyzed, 582 showed mental foramen on both sides. In 10 males and 8 females, the mental foramen could not be identified on both the sides. These were classified as "unidentified type" of mental foramen and excluded from the study. Hence a total of 582 panoramic radiographs were finally analysed. Out of these, 290 were males and 292 were females. The results are shown in Table 1-3 for horizontal plane and Table 4-6 for vertical plane.

In horizontal plane, in $61 \%$ of the cases, the mental foramen was in line with second premolar in both the left and right sides while in $28.7 \%$ of the cases the mental foramen was between the first and second premolar. It was symmetrical in $86.8 \%$ of the cases. In asymmetrical cases also, it was more commonly found below the second premolar $(45.5 \%)$ followed by in between first and second premolars $(24.7 \%)$ (Table 1-3).

In vertical plane the highest percentage of mental foramen was found to be located inferior to the apex of second premolar $(72.2 \%)$ followed by the position at or in line with the apex of second premolar $(21.6 \%)$. It was symmetrical in $91.8 \%$ (534 out of 582) of the cases. In asymmetrical cases also, it was more commonly found inferior to the apex of second premolar in $45.8 \%$ of the cases followed by at or in line with the apex of second premolar in $42.7 \%$ cases. Further, both males and females exhibit similar pattern of mental foramen distribution in horizontal as well as in vertical planes.

\section{DISCUSSION}

The accurate identification of the mental foramen is important for both diagnostic and clinical procedures. The men- tal foramen has been reported to vary in position in horizontal as well as vertical planes in different ethnic groups. Repeated failures during injections and operative procedures involving the mental foramen suggest the presence of local differences in a given population [5].

The location of the mental foramen has been studied by using radiographs of patients or by means of direct measurement on dry mandibles [9]. In this study, digital panoramic radiographs were used because they have certain advantages over conventional panoramic as well as intra-oral radiographs. It offers greater clarity of the mental foramen with less intra-observer difference in calculations. Further, it includes a greater area of hard and soft tissues and also the visualized area in continuity, thus allowing for a more accurate localization of the mental foramen in both the horizontal and vertical dimensions. On the other hand, periapical radiographs may not reveal the position of the mental foramen if it is below the edge of the film $[10,11]$.

Many studies have already delineated the location of these foramina in relation to bony and soft tissue landmarks. However, the landmarks used are often difficult to locate by palpation, diminishing their usefulness for predicting the locations of foramina in surgery. One of the bony landmarks previously used to locate the MF is the lower teeth. There are no absolute anatomical landmarks for reference and the foramen cannot be clinically visualized or palpated. As a result, the reported anatomical position of the mental foramen has been variable $[10,12]$. Most studies and textbooks however, describe the location of the mental foramen as being below the apex of the second premolar or between the apices of the first and second premolars $[10,12,13]$.

The possibility of the mental foramen occurring as far posterior as the apices of the first molar tooth is of clinical importance since the foramen in this area may be incorrectly interpreted on the radiograph as a pathosis.

In the literature mental foramen is closely associated with the lower second premolar and the space between the first and second premolars [9-11, 14-16] but individual variations do occur occasionally. According to Ngeow WC in 2003, of the current readily available books on dental analgesia, nine indicate that the mental foramen is mostly found between the apices of the first and second premolar. Although this is in accord with the results of the earlier studies of some Europian populations, it ignores completely a mass of most recent data and is therefore misleading [2, 9, 10, 12, 13, 17].

In this study, the horizontal position of mental foramen was anywhere between anterior to the first premolar to that of mesiobuccal root of first molar. This is in accordance with the previous reports in the literature $[2,6,12]$. The most common position of mental foramen was in line with second premolar $(61 \%)$ in both the left and right sides while in $28.7 \%$ of the cases the mental foramen was between the first and second premolar. These two positions make overall prevalence of $88.7 \%$.

The most popular method for identification of MF was proposed by Fishel et al. [6] and Green [17]. Fishel et al. in 1976 investigated vertical MF position and reported that in the first premolar area of 936 patients, the MF was situated superior to the apex in $46.0 \%$ of cases, inferior to the apex in 
Table 1. Frequency of location of the mental foramen in relation of the apices of teeth and interdental spaces on the panoramic radiographs of 582 Indian patients.

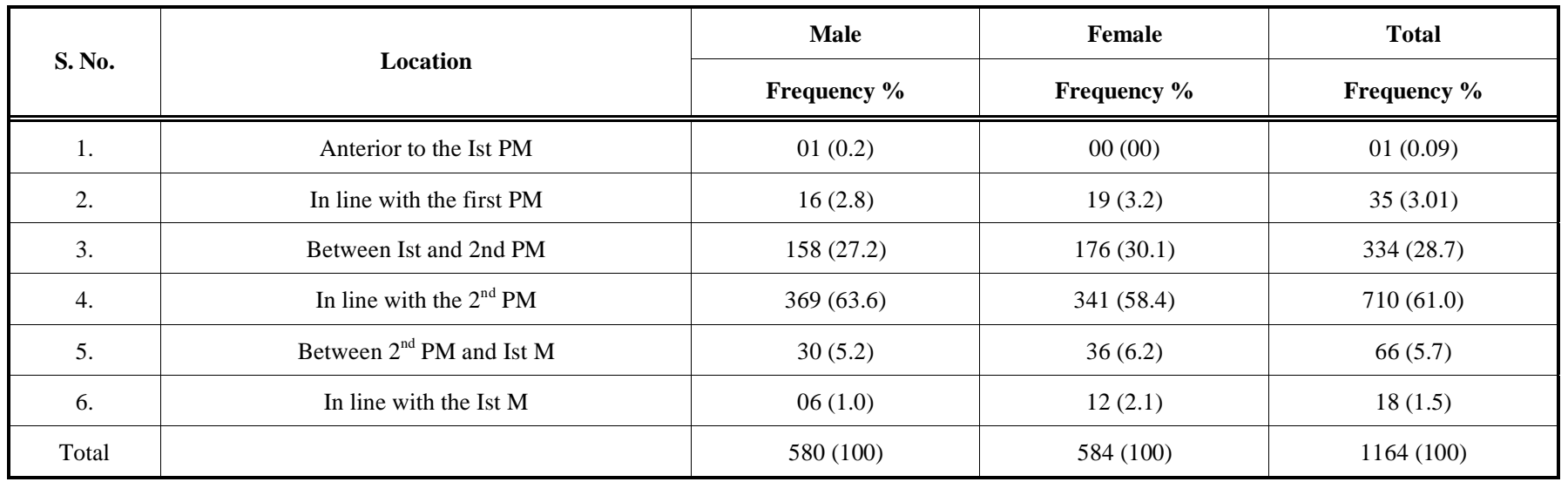

Table 2. Distribution of asymmetric Mental foramen in relation to the apices of teeth and interdental spaces of 77 patients.

\begin{tabular}{|c|c|c|c|c|}
\hline S. No & Location of Mental foramen & $\mathbf{R} \%$ & $\mathrm{~L} \%$ & Total \% \\
\hline 1. & Anterior to Ist premolar & $01(1.2)$ & $00(00)$ & $01(0.6)$ \\
\hline 3. & Between Ist and $2^{\text {nd }}$ premolar & $08(9.4)$ & $30(43.5)$ & $38(24.7)$ \\
\hline 4. & In line with $2^{\text {nd }}$ premolar & $44(51.8)$ & $26(37.7)$ & $70(45.5)$ \\
\hline \multirow[t]{2}{*}{6.} & In line with Ist molar & $02(2.3)$ & $04(5.8)$ & $06(3.9)$ \\
\hline & Total & $85(100)$ & $69(100)$ & $154(100)$ \\
\hline
\end{tabular}

Table 3. Distribution of symmetric mental foramen in relation to apices of the teeth and interdental spaces on panoramic radiographs of 505 Indian patients.

\begin{tabular}{|c|c|c|c|}
\hline S.No. & Location of Mental Foramen & Number & Percentage \\
\hline \hline 1. & Anterior to Ist premolar & $\mathbf{0 0}$ & $\mathbf{0 0}$ \\
\hline $\mathbf{2 .}$ & In line with Ist premolar & $\mathbf{1 3}$ & $\mathbf{2 . 6}$ \\
\hline $\mathbf{3 .}$ & Between Ist and 2 ${ }^{\text {nd }}$ premolar & $\mathbf{1 4 8}$ & $\mathbf{3 2 0}$ \\
\hline 4. & In line with 2 ${ }^{\text {nd }}$ premolar & $\mathbf{1 8}$ & $\mathbf{6 3 . 4}$ \\
\hline $\mathbf{5 .}$ & Between 2 $2^{\text {nd }}$ premolar and Ist molar & $\mathbf{0 6}$ & $\mathbf{1 . 2}$ \\
\hline 6. & In line with Ist molar & $\mathbf{5 0 5}$ & $\mathbf{1 0 0}$ \\
\hline
\end{tabular}

$38.6 \%$ of cases, at the apex in $15.4 \%$ of cases. The MF location, in relation to the second premolar, was superior to the apex in $61.6 \%$ of cases, inferior to the apex in $24.5 \%$ of cases, at the apex in $13.9 \%$ of cases. In contrast to the findings of Fishel et al. the vertical position of the mental foramen in this study with our criteria resulted in the highest percentage of mental foramen to be located inferior to the apex of second premolar $(72.2 \%)$ followed by the position at or in line with the apex of second premolar (21.6\%). It was symmetrical in $91.8 \%$ (534 out of 582) of the cases.
The radiographs in this study were taken with Orthophos XG 5 DS Ceph by Sirona. With proper patient positioning, there will usually be limited horizontal overlap of the teeth. None the less, errors in patient positioning, as well as variations in facial morphology can lead to mesial and distal angulation of the Xray beam. However, comparative studies on dry skulls have shown a close correlation with the radiographic location of the mental foramina $[8,12,16-20]$. It is therefore probable that the shift in the actual posteroanterior position of the mental foramen in panoramic radiographs is insignificant [2]. 
Table 4. Frequency of location of the mental foramen in vertical plane in relation to the apices of teeth and interdental spaces on the panoramic radiographs of 582 Indian patients.

\begin{tabular}{|c|c|c|c|c|}
\hline S. No. & Location & Male & Female & Total \\
\hline 2. & At or in line to the apex of first premolar & $08(1.4)$ & $19(3.2)$ & $27(2.3)$ \\
\hline 3. & In between the apex of Ist and 2nd premolar & $12(2.1)$ & $22(3.8)$ & $34(2.9)$ \\
\hline 5. & Inferior to the apex of $2^{\text {nd }}$ premolar & $436(75.2)$ & $404(69.2)$ & $840(72.2)$ \\
\hline Total & & $580(100)$ & $584(100)$ & $1164(100)$ \\
\hline
\end{tabular}

Table 5. Distribution of asymmetric Mental foramen in vertical plane in relation to the apices of teeth of 48 patients.

\begin{tabular}{|c|c|c|c|c|}
\hline 1. & Superior to the apex of Ist premolar & $02(4.2)$ & $00(00)$ & $02(2.1)$ \\
\hline 3. & In between the apex of Ist and 2 nd premolar & $03(6.4)$ & $03(6.1)$ & $06(6.3)$ \\
\hline 4. & At or in line with the apex of $2^{\text {nd }}$ premolar & $23(48.9)$ & $18(36.8)$ & $41(42.7)$ \\
\hline 5. & Total & $47(100)$ & $49(100)$ & $96(100)$ \\
\hline
\end{tabular}

Table 6. Distribution of symmetric mental foramen in vertical plane in relation to apices of the teeth of 534 patients.

\begin{tabular}{|c|c|c|c|}
\hline 1. & Superior to the apex of Ist premolar & 05 & 0.9 \\
\hline 3. & In between the apex of Ist and 2nd premolar & 14 & 2.6 \\
\hline 4. & At or in line with the apex of $2^{\text {nd }}$ premolar & 105 & 19.7 \\
\hline 5. & Total & 534 & 100 \\
\hline
\end{tabular}

It is evident from the studies in the literature that location of $\mathrm{MF}$ is related with race. For example, the position of the $\mathrm{MF}$ in the Mongoloid population was in line with the longitudinal axis of second lower premolar. Their positions in Caucasoid samples were just mesial to those in Chinese, Melanesian, Asian Indians, Thai, Korean, Saudi and Tanzanian samples. It is very unusual to find foramen located anteriorly by the canine or posteriorly beyond the first molar.

In jaws in which the mental foramen is not exposed on the top of the alveolar crest, the anatomical foramen is situated higher than the radiographically detectable foramen. This is actually an image of a part of the rising terminal part of the mental canal. The differences in the position of the anatomical foramina between the dentulous and the edentulous are thus in fact greater than the radiographic values re- ported here, because the mental canal was not present in the majority of the edentulous due to alveolar atrophy [21]. Vertical measurements can be made from panoramic radiographs with an accuracy of 0-13-0-21 mm, and the measurement error is smallest in the lower premolar region, where the mental foramen is located. Small differences in the positioning of the head do not have any significant effect on the location of the radiographically detectable foramen in panoramic radiography $[7,8]$.

\section{CONCLUSION}

The aim of this study was to familiarize new criteria to access vertical position of mental foramen in panoramic radiographs. Furthermore, it was concluded that when compared to other studies in the literature, mental foramen exists 
in different locations and possesses many variations. Hence, Individual, gender, age, race and assessing technique largely influence these variations. It suggests that the clinicians should carefully identify these anatomical landmarks, by analyzing all influencing factors, prior to their diagnostic or the other dental, surgical and implant operation.

\section{CONFLICT OF INTEREST}

The authors confirm that this article content has no conflict of interest.

\section{ACKNOWLEDGEMENTS}

Declared none.

\section{REFERENCES}

[1] Ilayperuma I, Nanayakkara G, Palahepitiya N. Morphometric analysis of the mental foramen in adult Sri Lankan mandibles. Int J Morphol 2009; 27: 1019-24.

[2] Al Jasser NM, Nwoku AL. Radiographic study of mental foramen in a selected Saudi Population. Dentomaxillofac Radiol 1998; 27: 341-3.

[3] Haghanifar S, Rokouei M. Radiographic evaluation of the mental foramen in a selected Iranian population. Indian J Dent Res 2009; 20: $150-2$.

[4] Greenstein G, Tarnow D. The mental foramen and nerve: clinical and anatomical factors related to dental implant placement: a literature review. J Periodontol 2006; 77: 1933-43.

[5] Amorim MM, Prado FB, Borini CB, et al. The mental foramen position in dentate and edentulous Brazilian's mandible. Int J Morphol 2008; 26: 981-7.

[6] Fishel D, Buchner A, Hershkowith A, Kaffe I. Roentgenologic study of the mental foramen. Oral Surg Oral Med Oral Pathol 1976; 41: 682-6. doi: 10.1013a/0030-4220(76)90325-X
[7] Yosue T, Brooks SL. The appearance of mental foramina on panoramic radiographs. II Experimental evaluation. Oral Surg Oral Med Oral Pathol 1989; 68: 488-92.

[8] Yosue T, Brooks SL. The appearance of mental foramina on panoramic radiographs. I Evaluation of patients. Oral Surg Oral Med Oral Pathol 1989; 68: 360-4

[9] Philips JL, Weller RN, Kulild JC. The mental foramen Part: 1. Size, orientation and positional relationship to the mandibular second premolar. J Endod 1990; 13: 221-3.

[10] Philips JL, Weller RN, Kulild JC. The mental foramen: Part 2. Radiographic position in relation to the mandibular second premolar. J Endod 1992; 18: 271-4.

[11] Philips JL, Weller RN, Kulild JC. The mental foramen: Part 3. Size and position on panoramic radiographs. J Endod 1992; 18: 383 -6.

[12] Shankland II, WE. The position of the mental foramen in Asian Indians. J Oral Impl 1994; 20: 118-23.

[13] Ngeow WC, Yuzawati Y. The location of mental foramen in a selected Malay population. J Oral Sci 2003; 45: 171-5.

[14] Montagu MFA. The direction and position of the mental foramen in the great apes and men. Am J Phys Anthrop 1954; 12: 503-18.

[15] Al Jasser NM, Nwoku AL. Radiographic study of the mental foramen in Saudi females. Saudi Med J 1996; 17: 471-4.

[16] Matsuda Y. Location of the dental foramina in human skulls from statistical observations. Am J Orthod 1927; 13: 299-305.

[17] Green RM. The position of the mental foramen. A comparison between the Southern (Hongkong) Chinese and other ethnic and racial groups. Oral Surg Oral Med Oral Pathol 1987; 63: 287-90.

[18] Lumnije K, Ensad S, Andreas W, Städtler WMW. Position of the mental foramen: an anatomical study. Collegium Antrotologicum 2011; 161: 272-3.

[19] Apinhasmit W, Methathrathip D, Chompoopong S, Sangvichien S. Mental foramen in Thais: an anatomical variation related to gender and side. Surg Radiol Anat 2006; 28(5): 529-33.

[20] Al-Khateeb T, Al-Hadi Hamasha A, Ababneh TK. Position of the mental foramen in a northern regional Jordanian population. Surg Radiol Anat 2007; 29: 231-7.

[21] Soikkonen K, Wolf J, Ainamo A and Xie Qiufei. Changes in the position of the mental foramen as a result of alveolar atrophy. J Oral Rehab 1995; 22: 831-3

\author{
Received: July 18, 2014 \\ Revised: October 30, 2014 \\ Accepted: May 25, 2015 \\ (C) Parnami et al.; Licensee Bentham Open.
}

This is an open access article licensed under the terms of the Creative Commons Attribution Non-Commercial License (http://creativecommons.org/licenses/by-nc/3.0/) which permits unrestricted, non-commercial use, distribution and reproduction in any medium, provided the work is properly cited. 